\title{
Investigation of Chip Morphology and Tool Wear during Hard Machining of Hard Chrome Plated EN24 Substrate
}

\author{
K.N. Mohandas, C.S. Ramesh, K. Eshwara Prasad and N. Balashanmugam
}

\begin{abstract}
Hard Chrome plated surfaces are used in automotive, aerospace and marine applications. The electroplated chrome surface has to undergo finishing processes before assembled for service. Improvements in the tool and coating technologies, varieties of tool options are available to machine surfaces with hardness more than 45HRc. The objective of this research is to find the influence of tool wear and the surface characteristics of the chrome surfaces. The wear characteristics of Polycrystalline Cubic Boron Nitride (PCBN) tool with different nose radius, tool angles are analyzed with varying machining parameters. The investigation helped choose the process as alternative to grinding for a specific length of cut. The chips produced by the hard turning were studied by Scanning Electron Microscope (SEM). The SEM analysis revealed that the chips produced were brittle in nature.
\end{abstract}

Keywords--- Hard Turning, Hard Chrome Plating, Chip Morphology, Flank Wear

$v=$ cutting speed, $\mathrm{rpm}$

$f=$ feed rate, $\mathrm{mm} / \mathrm{rev}$

DOC, $d=$ depth of cut, $\mu \mathrm{m}$

\section{INTRODUCTION}

$\mathrm{H}$ ARD turning is studied in detail recently for the ease that it offers as compared to grinding. Though the surface roughness is not much encouraging in comparison with grinding, yet hard turning provides other advantages like: operational flexibility, cycle time reduction, minimal lubrication etc. The machine that is used for hard turning to achieve excellent surface characteristics plays an important role in understanding the process capability. Hard Chrome plated surfaces find wide applications in the aerospace and marine industries. Hard Chrome generally has to undergo grinding after plating to bring a leveled surface before putting

K.N. Mohandas, Assistant Professor, Department of Mechanical Engineering, M S Ramaiah Institute of Technology, Bangalore, India. E-Mail: mohandaskn@gmail.com

Dr.C.S. Ramesh, Professor, Department of Mechanical Engineering, PES Institute of Technology, Bangalore, India. E-Mail: csr_gce@yahoo.co.in

Dr.K. Eshwara Prasad, Professor, Department of Mechanical Engineering, JNT University, Hyderabad, India. EMail:epkoorapati@gmail.com

N. Balashanmugam, HOD \& Scientist-E, Central Manufacturing Technology Institute, Bangalore, India. E-Mail:balashanmugam@cmtiindia.net

DOI: 10.9756/BIJIEMS.1870 it into service. However the tool technology and the machines were not sophisticated to try machining of chrome [1]. The tool that has to machine chrome plating has to be harder than the work-piece. The chrome plating has a hardness of around $60-70 \mathrm{HRc}$ and the tools that suit this type of machining is found to be PcBN $[2,3]$. To attain good accuracies in hard turning of chrome surfaces the machine that is used for this process has to be rigid and free from a good amount of chatter and vibrations [4].

The tool wear is an influencing factor in deciding the surface integrities of the work. Tool wear during machining occurs mainly because of friction that occurs between the cutting edge and the work-piece. Thus, a detailed study in the tool temperatures and the wear will help decide the right machining parameters in machining hard chrome. The tool wear due to adhesion and abrasion has been studied extensively [5]. Some of the wear mechanisms have been studied and can be summarized into 5 types or a combination of two or more during machining [6].

The different types of wear when machining are due to abrasion, adhesion, fatigue, and dissolution/diffusion and tribo-chemical process [7]. Tool wear is an important parameter when the surface integrities of a material are investigated. The extreme hardness values of chrome surfaces were interesting enough to investigate the effect of tool wear during hard turning.

The formation of chips during machining reveals the mechanism of metal cutting. Continuous chips are produced while machining ductile material with proper cutting conditions. Normally machining harder materials discontinuous chips are produced. These chips are having impact on the surface produced, temperature developed and power required for the machining [8]. In the present investigation, the authors have carried out the analysis of the chips produced in hard turning of hard chrome plated surfaces. The study of chips is vital for the optimizing the machining conditions. The authors also observed the microscopic changes in the hard turned specimen using SEM. The change in microstructure leads to the change in some of the properties of the machined components.

\section{EXPERIMENTAL PROCEDURE}

\subsection{Material Selection}

The present experiment involves the use of a hard chrome plated specimen as a work piece in the turning process. EN24 was selected as the base material to coat hard chrome plating. 
EN24 is a high quality, high tensile, alloy steel, it combines high tensile strength, shock resistance, good ductility and resistance to wear. Base material was selected with dimension of $50 \mathrm{~mm}$ diameter and $70 \mathrm{~mm}$ length. Machining length selected was $50 \mathrm{~mm}$. Chemical compositions in weight percentage of EN24 substrate was measured by spectroscope and is given in Table 1.

Table 1: Chemical Composition in Weight Percentage

\begin{tabular}{|c|c|c|c|c|c|c|c|}
\hline $\mathrm{C}$ & $\mathrm{Si}$ & $\mathrm{Mn}$ & $\mathrm{S}$ & $\mathrm{P}$ & $\mathrm{Ni}$ & $\mathrm{Cr}$ & $\mathrm{Mo}$ \\
\hline 0.38 & 0.35 & 0.57 & 0.011 & 0.019 & 1.37 & 1.06 & 0.22 \\
\hline
\end{tabular}

\subsection{Machine Tool and Cutting Tool Selection}

Hardinge Quest 8/51 Special Purpose lathe was considered as the machine tool for conducting hard turning owing to its surface finish capabilities and rigidness. The set-up of the workpiece on hard turning machine is shown in figure 1.

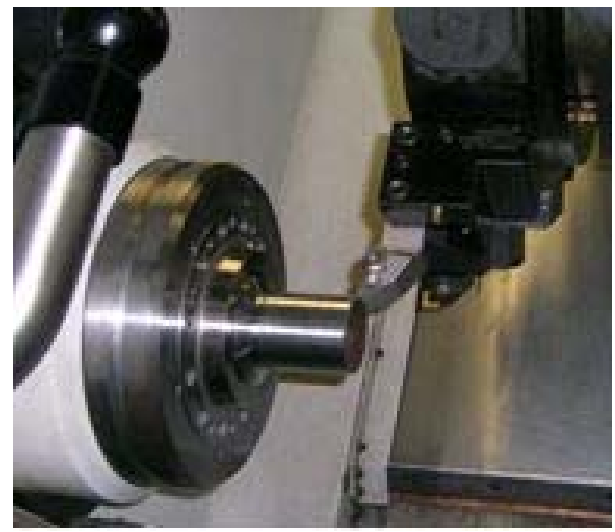

Figure1: Set-up of the Hard Chrome Coating on the Hard Turning Machine

The Titanium Aluminium Nitride (TiAlN) coated PcBN inserts were considered with varying cutting edge angles and nose radii. The Mitsubishi tools that were used in experiments are shown in Table.2. Poly Crystalline CBNs are manufactured by sintering the individual $\mathrm{CBN}$ crystals together or bonding with binder materials such as ceramic binders to form a large mass.

Table 2: Tools Used in Experimentations

\begin{tabular}{|c|c|c|c|}
\hline $\begin{array}{c}\text { SL. } \\
\text { No. }\end{array}$ & INSERT & $\begin{array}{c}\text { CUTTING } \\
\text { ANGLE }\end{array}$ & $\begin{array}{c}\text { NOSE RADIUS } \\
(\mathrm{mm})\end{array}$ \\
\hline 1. & CNGA 120404 & $80^{\circ}$ & 0.4 \\
\hline 2. & CNGA 120408 & $80^{0}$ & 0.8 \\
\hline 3. & DNGA 150404 & $55^{0}$ & 0.4 \\
\hline 4. & DNGA 150408 & $55^{0}$ & 0.8 \\
\hline
\end{tabular}

The cutting parameters were selected based on the literature survey and the requirement of the job available at Central Manufacturing Technology Institute for their R\&D work. Taguchi's L9 orthogonal array (OA) of experiments was used to find out the most affecting factor in deciding the parameters chosen. The earlier experiments to find the cutting forces by the same authors have revealed that the lesser the cutting speed lesser the cutting force developed and better the tool life [9]. Table 3 shows the cutting parameters and the levels selected for the experimentations and table 4 shows the Design of Experimentation (DoE) adopted.

Table 3: Cutting Parameters with Levels

\begin{tabular}{|c|c|c|c|}
\hline Parameters & Level 1 & Level 2 & Level 3 \\
\hline $\begin{array}{c}\text { Cutting speed } \\
(\mathrm{rpm}), v\end{array}$ & 300 & 400 & 500 \\
\hline $\begin{array}{c}\text { Feed }(\mathrm{mm} / \mathrm{rev}) \\
f\end{array}$ & 0.04 & 0.06 & 0.08 \\
\hline $\begin{array}{c}\text { Depth of cut } \\
(\mu \mathrm{m}), d\end{array}$ & 40 & 80 & 120 \\
\hline
\end{tabular}

Table 4: Levels and Factors of Experimentation (L9 OA)

\begin{tabular}{|c|c|c|c|}
\hline Trail No. & Speed (rpm) & $\begin{array}{c}\text { Feed } \\
(\mathrm{mm} / \mathrm{rev})\end{array}$ & $\begin{array}{c}\text { Depth of } \\
\text { Cut }(\mu \mathrm{m})\end{array}$ \\
\hline 1 & 300 & 0.04 & 40 \\
\hline 2 & 300 & 0.06 & 80 \\
\hline 3 & 300 & 0.08 & 120 \\
\hline 4 & 400 & 0.04 & 120 \\
\hline 5 & 400 & 0.06 & 40 \\
\hline 6 & 400 & 0.08 & 80 \\
\hline 7 & 500 & 0.04 & 80 \\
\hline 8 & 500 & 0.06 & 120 \\
\hline 9 & 500 & 0.08 & 40 \\
\hline
\end{tabular}

\subsection{Flank Wear Measurement}

The confocal microscope was used to measure the flank wear developed on the cutting inserts. The inserts were kept on the V-block under the confocal microscope and with various focal lenses the images were enlarged. Figure 2 shows the above set-up to measure the flank wear. The length of cut of the experimentation was decided as $10 \mathrm{~mm}$.

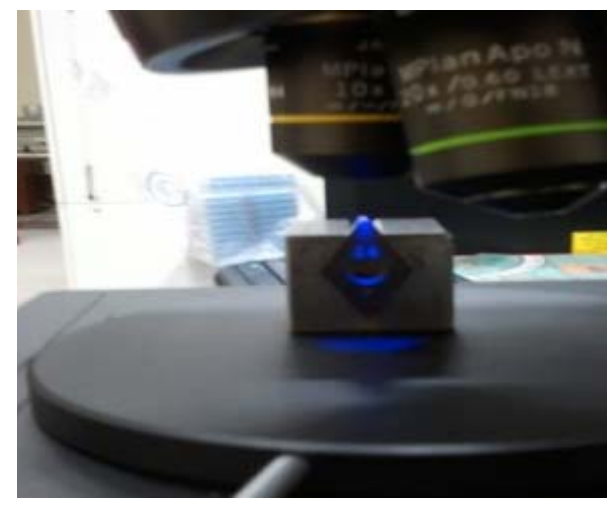

Figure 2: Measurement of Flank Wear on Confocal Microscope

\subsection{Chip Morphology}

The chips produced from the hard turning of hard chrome plated surfaces were collected to study the chip morphology. The chips were observed under the Scanning Electron Microscope to study the nature of the fracture. 


\section{RESULTS}

\subsection{Flan wear}

The flank wear on each of the tools were measured and tabulated. Table 5 shows the results of all the four different inserts used in the experimentation.

Table 5: Comparative Values of the Flank Wear

\begin{tabular}{|c|c|c|c|c|}
\hline $\begin{array}{c}\text { TRIAL } \\
\text { NO. }\end{array}$ & $\begin{array}{c}\text { CNGA } \\
120404(\mathrm{~A})\end{array}$ & $\begin{array}{c}\text { CNGA } \\
120408(\mathrm{~B})\end{array}$ & $\begin{array}{c}\text { DNGA } \\
150404(\mathrm{C})\end{array}$ & $\begin{array}{c}\text { DNGA } \\
150408(\mathrm{D})\end{array}$ \\
\hline 1 & 131 & 124 & 92 & 131 \\
\hline 2 & 106 & 120 & 84 & 108 \\
\hline 3 & 146 & 110 & 115 & 65 \\
\hline 4 & 195 & 267 & 135 & 137 \\
\hline 5 & 123 & 130 & 95 & 127 \\
\hline 6 & 129 & 105 & 97 & 100 \\
\hline 7 & 146 & 120 & 152 & 117 \\
\hline 8 & 74 & 135 & 117 & 70 \\
\hline 9 & 121 & 135 & 82 & 90 \\
\hline
\end{tabular}

The trials included a change in the depth of cut. The tool wear increased with the depth of cut at lower speeds in inserts of $80^{\circ}$ and $55^{\circ}$ cutting edge angles of same nose radius of $0.8 \mathrm{~mm}$. But, the tool wear showed a decreasing pattern in Tool $80^{\circ}$ and $55^{\circ}$ cutting edge angles with nose radius of $0.4 \mathrm{~mm}$ with increase in the depth of cut at lower speeds. Fig.3 shows the variation of tool wear as the trials proceeded.

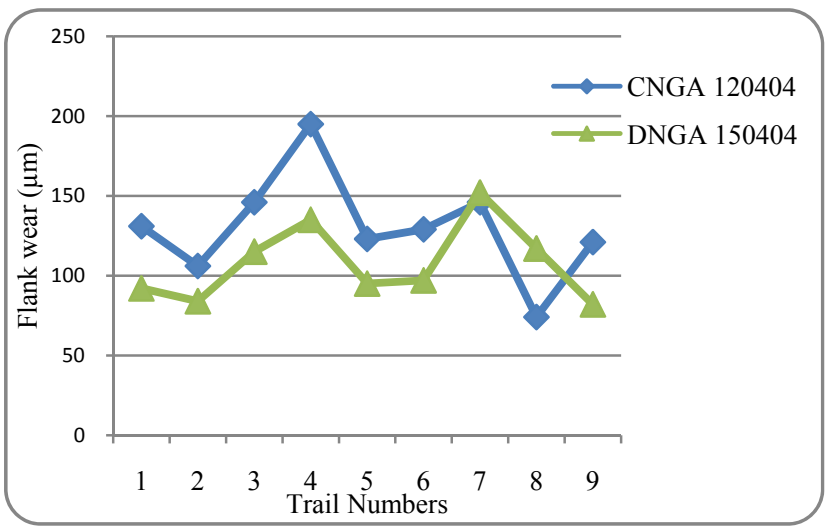

Figure 3: Comparative Graph of the Flank Wear for CNGA 120404 and DNGA 150404 Inserts

Cutting angle of $55^{\circ}$ inserts worn out with a faster rate when compared with $80^{\circ}$ cutting angle. This was observed due to the fact that $80^{\circ}$ cutting angle insert showed more wear resistance compared to $55^{\circ}$. Fig. 4 shows a variation in the tool wear for different cutting speeds when depth of cut is constant of $40 \mu \mathrm{m}$. At this depth of cut we can observe that the insert with $0.8 \mathrm{~mm}$ nose radius have lesser wear as compared to insert with $0.4 \mathrm{~mm}$ nose radius.

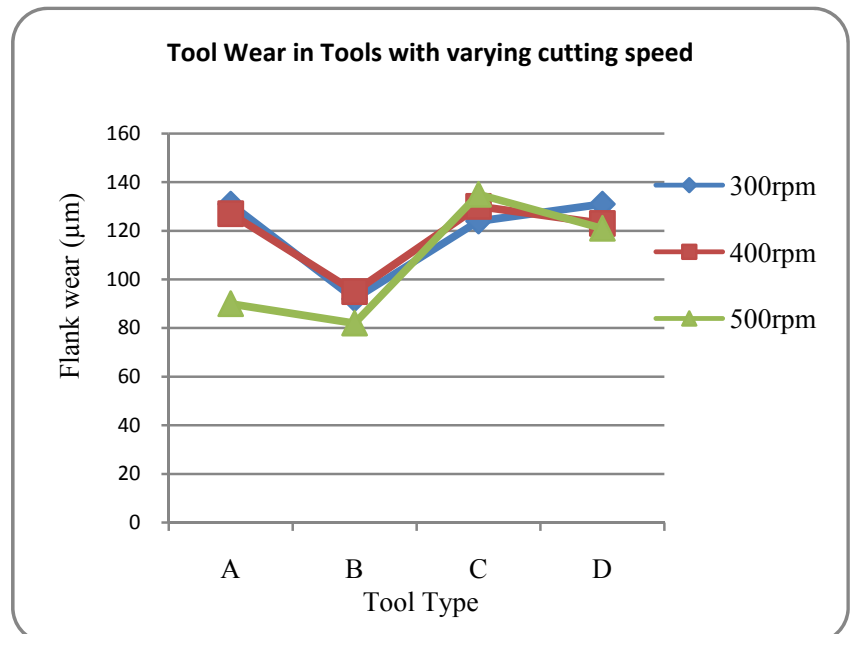

Figure 4: Comparative Studies of the Flank Wear at Varying Cutting Speed

\subsection{Chip Morphology}

The study of the chips during turning of materials play an important role in the surface finish achieved in the machining process. The chips produced by hard turning of hard chrome plated surfaced were collected to study the behavior. The nature of failure of the chip was observed under the confocal microscope. The image of the confocal microscope is shown in figure 5. The confocal microscope images revealed the saw tooth type of failure of the chrome plated surfaces in the form of chips.



Figure 5: Image of the Chip Observed Under Confocal Microscope

To study the nature of fracture of the chip higher magnification was required. Due to this reason these chips were observed under SEM to study the chip morphology. Figure 6 is the SEM image of the chip collected during hard turning of hard chrome plated surfaces. 


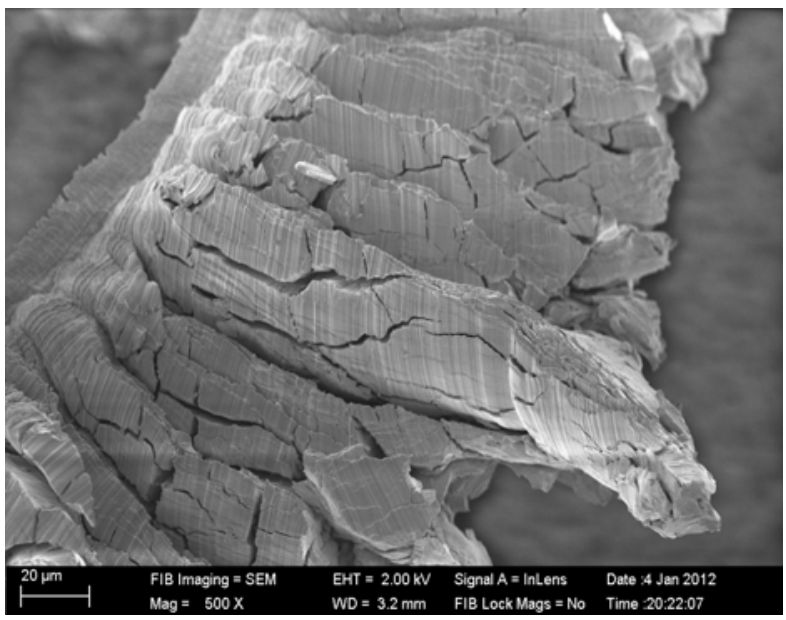

Figure 6: SEM Image of the Chip Produced

When observed under SEM, the chips produced showed the nature of fracture of these from the work piece. There was a brittle kind of fracture observed at a magnification of 500X. The images showed that the failures of chips were brittle in nature. These types of fractures were observed in all the different cutting conditions. This showed that the chrome plated surface detached from the work piece as soon as the metal cutting started. This could be one of the reasons for getting comparatively less temperature during finish turning of chrome plated surfaces. The pictures clearly indicated that the chips were saw-tooth type of chips which occurs during hard turning. The average lengths of the chips observed were in the range of $1 \mathrm{~mm}$ and the average width $100-150 \mu \mathrm{m}$. The SEM images were shown in the figures 7 and 8 .



Figure 7: The Average Width Measurement of the Chip

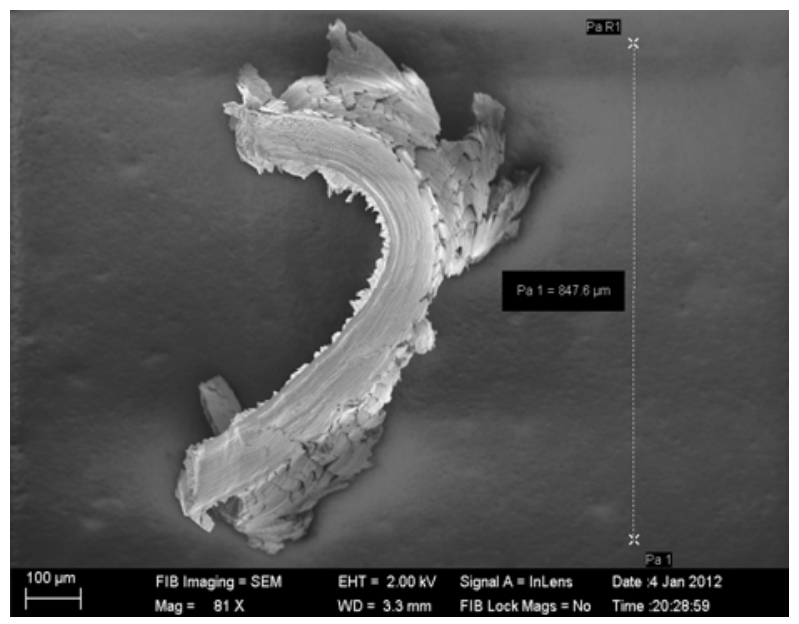

Figure 8: The Average Length Measurement of the Chip

The chips showed curled pattern indicating excessive stress during removal from the uncut part. At higher resolutions chips showed excessive cracking which clearly indicates brittle fracture through crack propagation.

\subsection{Microstructure}

The micro-structural observations carried on the chrome plated surfaces showed a good bonding between the chrome plated surfaces and the EN24 substrate. Though at higher magnifications there was a gap in the coating which was observed. The further magnification images indicated that there could be a better coating technique adapted to decrease the gaps in the coating.

The micro structure image showed the plating and the base material, the base material has a lot of unfilled gaps which can be observed which will enhance corrosion, but the chrome surface is closely packed avoiding corrosion and providing extreme hardness on the surface to resist wear. Figure 9 shows the SEM image at $100 \mathrm{X}$ magnification.

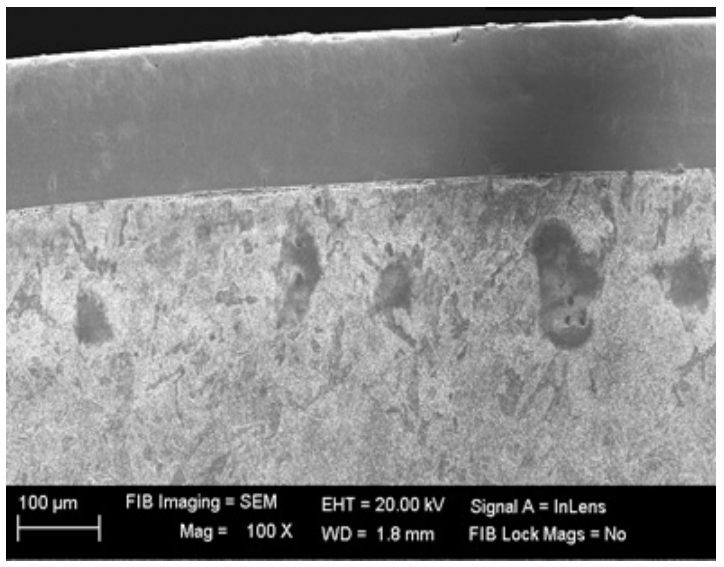

Figure 9: SEM Image of the Hard Turned Chrome Plated Surface at $100 \mathrm{X}$

When moved to higher magnifications such as 250X and further the hard chrome coating showed the microstructures clearly. White patches were observed when the magnification was at 250X. Figure 10 shows the chrome plating at a magnification of $250 \mathrm{X}$. 


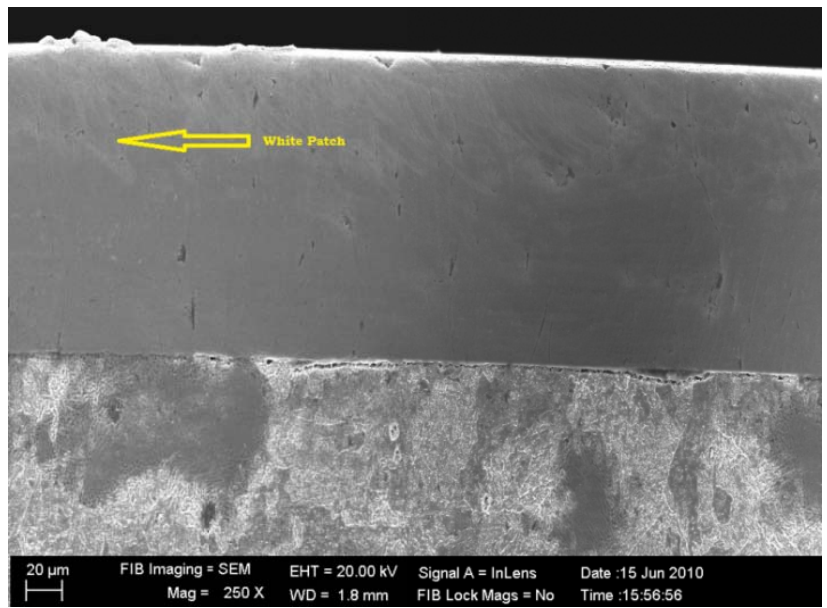

Figure 10: SEM Image of the Hard Turned Chrome Plated Surface at $250 \mathrm{X}$

This may be due to the tool path on the chrome plated surfaces. A detailed study on this required to conclude the nature of these white patches. The bonding of the coating with EN24 base material showed acceptable strength at the magnification of $10 \mathrm{kX}$. Figure 11 shows the bonding of the chrome plating on the EN24 substrate. The appearance of micro-cracks by SEM images at $10 \mathrm{kX}$ suggested that the coating parameters to be controlled properly. The hardness of the coating increases with the presence of micro-cracks but decreases the resistance to corrosion and the fatigue strength. These micro-cracks permit the lubrication to pierce the surface thereby extending the life of the coating on the substrate. The absence of these micro-cracks increases the wear rate by softening the coating. Therefore the literatures have suggested that the mixture of both micro-cracks and the smooth surfaces exhibit increased fatigue strength, corrosion and wear resistance.

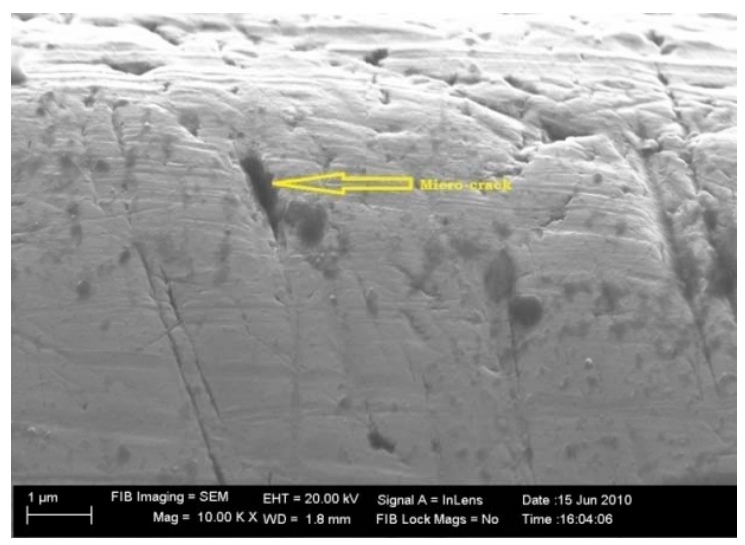

Figure 11: SEM Image of the Hard Turned Chrome Plated Surface at $10 \mathrm{kX}$

\section{CONCLUSION}

After detailed study on the tool wear during hard turning of chrome plated surfaces following conclusions are drawn:

1. The chips produced by hard turning of hard chrome plated surfaces were in the saw tooth form. The chips were detached from the work piece as soon as the cut initiated.

2. The wear in the tool increases with the cutting depths and the length of cut thus resulting in a lower surface finish.

3. Some tools showed a chipping effect due to larger depth of cut and higher cutting speeds. Though the surface initially was good the chipping had a great effect on the lower surface finish. The chipping which was absent at medium cutting speeds reduced the tool wear.

4. The tool wear was low at medium speeds and lower depth of cut and medium feed rate.

5. The tool nose radius directly influences the tool wear when considered with depth of cut. The tool with larger nose radius increases wear as DOC increases and is vice versa for lower tool nose radius.

6. The observation of chips confirms the failure mode which is brittle in nature through crack propagation.

7. The SEM images revealed that less micro structural changes took place during hard turning of hard chrome plated surface. This could be one of the reasons for less variation observed in hardness of the hard chrome plated surfaces and the hard turned surfaces.

\section{ACKNOWLEDGEMENTS}

This work is a portion of the on-going research project number: SR/S3/MERC-0113/2009 sanctioned by DST under SERC scheme.

The authors would like to acknowledge Mr. B.R. Satyan, Director - CMTI, Mr. P.V. Shashikumar, Joint Director and Project guide - CMTI and authorities of DST for facilitating this research under the funding of DST.

\section{REFERENCES}

[1] Vitor Augusto A. De Godoy, Anselmo Eduardo Diniz, "Turning of interrupted and continuous hardened steel surfaces using ceramic and CBN cutting tools", International Journal of Materials Processing Technology, Volume 211, Pp. 1014-1025, 2011.

[2] Gaurav Bartarya, S.K. Choudhury, "State of the art in hard turning", International Journal of Machine Tools \& Manufacture, Volume 53, Pp. $1-14,2012$.

[3] Kurt Adair, Shiv G. Kapoor, E. Richard, "Development of a unique topology for a hard-turning micro-scale machine tool", DeVor, J of Manufacturing Processes, Volume 13, Pp. 75-84, 2011.

[4] F.A. Almeida, A.J.S. Fernandes, F.J. Oliveira, R.F. Silva, "Semi orthogonal turning of hard metal with CVD diamond and PCD inserts at different angles", Vacuum, Volume 83, Pp. 1218-1223, 2009.

[5] H.H. Shahabi, M.M. Ratnam, "Assessment of flank wear and nose radius wear from workpiece roughness profile in turning operation using machine vision", International Journal of Advanced Manufacturing Technology, Volume 43,Pp. 11-21, 2009.

[6] J. Kundrak, B. Karpuschewski, K. Gyani, V. Bana, "Accuracy of hard turning, J of materials processing technology, Volume 202, Pp. 328$338,2008$.

[7] I.S. Kang, J.S. Kim, Y.W. Seo, "Investigation of cutting force behavior considering the effect of cutting edge radius in the micro-scale milling of AISI 1045 steel", Journal of Engineering Manufacture, Proc. IMechE, Volume 225, Pp. 163-171, 2011.

[8] D.I. Lalwani, N.K. Mehta, P.K. Jain, "Experimental investigations of cutting parameters influence on cutting forces and surface roughness in finish hard turning of MDN250 steel", J of materials processing technology, Volume 206, Pp. 167-179, 2008. 
[9] K.N. Mohandas, C.S. Ramesh, K. Eshwar Prasad, N. Balashanmugam and P.V. Shashikumar "Study of the flank wear during hard turning of hard chrome plated surfaces", Int. Conference of Material Processing and Characterization, Hyderabad, Pp. 168-173, 2012.

[10] M. Dogra, V.S. Sharma, J. Dureja, "Effect of tool geometry variation on finish turning - A Review", J of Engineering Science and Technology, Volume 4, No. 1, Pp. 1-13, 2011.

[11] Ilhan Asilturk, Harun Akkus, "Determining the effect of cutting parameters on surface roughness in hard turning using the Taguchi method", Measurement, Volume 44, Pp. 1697-1704, 2011.

[12] Gerard Poulachon, Alphonse L. Moisan, "Hard Turning - Chip formation mechanisms and Metallurgical aspects", ASME, Volume 122, Pp. 406-412, 2000.

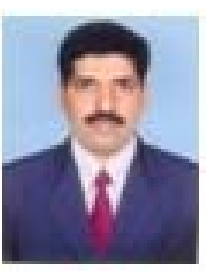

K.N. Mohandas has born at Honavar (Karnataka) on 02nd October, 1977. The author obtained his B.E. degree in Mechanical Engineering from National Institute of Engineering, Mysore in the year 1999 and M.E. degree from UVCE, Bangalore in Manufacturing Science and Engineering in the year 2003. The author's major field of study is in the area of metal cutting. The author is the coinvestigator of a DST sponsored R\&D project in collaboration with Central Manufacturing Technology Institute (CMTI), Bangalore. He is pursuing his $\mathrm{PhD}$ degree in JNT University, Hyderabad in the area of Hard Turning under the guidance of Dr. C.S.Ramesh, Professor, PES Institute of Technology, Bangalore and Dr.

K. Eshwara Prasad, Professor, JNT University, Hyderabad. 